Check for updates

New York

Cite this as: $B M J$ 2020;371:m4799 http://dx.doi.org/10.1136/bmj.m4799 Published: 11 December 2020

\title{
Covid-19: FDA panel votes to authorise Pfizer BioNTech vaccine
}

\section{Janice Hopkins Tanne}

The US Food and Drug Administration's (FDA) independent panel of experts voted on 10 December in favour of emergency use authorisation for the Pfizer BioNTech covid-19 vaccine. The FDA is expected to approve the vaccine within days. Distribution to the states would then begin immediately. Full FDA approval will likely follow.

The one day hearing of the Vaccines and Related Biological Products Advisory Committee was broadcast live on YouTube, Twitter, and Facebook. Questions were raised about the safety of the vaccine in people who have had severe allergic reactions and carry an epinephrine injection device, after two allergic reactions were reported in the UK following vaccination. ${ }^{1}$ Paul Offit, a vaccine expert at the Children's Hospital of Philadelphia, said that "tens of millions of Americans" might be at risk because of such allergies. The committee also questioned giving the vaccine to people aged 16 or 17 and to women who are pregnant or lactating. The committee voted 17-4 in favour of approving the vaccine with one abstention.

Next week the FDA will consider emergency use authorisation for Moderna's covid-19 vaccine.

Pfizer has said it expects to produce 50 million doses of its vaccine this year and 1.3 billion by the end of 2021. ${ }^{2}$ Each person vaccinated is to receive two doses about a month apart. If approved, Moderna could provide 100 million doses of its vaccine, which also requires two injections. ${ }^{3}$

Several months ago, Pfizer offered the Trump administration an opportunity to secure additional supplies of its vaccine, but the offer was not accepted and the additional supplies were ordered by other countries, the New York Times reported. ${ }^{4}$ Alex Azar, secretary of health and human services, denied the story.

The Pfizer BioNTech vaccine is expected to be offered first to healthcare workers, then to residents and staff of care homes, essential workers, adults with high risk conditions, people 65 and older, and then to the rest of the population.

The committee meeting came on a day when the US saw a record number of cases, hospitalisations, and deaths. As of 10 December, the US had a total of 15 600,00 cases and 292000 deaths, ${ }^{5}$ with 218690 new cases and 3157 new deaths. ${ }^{6}$

On 9 December, Michelle Williams, dean of the Harvard TC Chan School of Public Health at Harvard, said there had been four million new cases in November and already one million cases in December. She spoke at a webinar sponsored by Harvard and the New England Journal of Medicine. Covid-19 was now the leading cause of death of Americans and the nation saw the "equivalent of Pearl Harbor" every day. She expressed concern about vaccine hesitancy and warned, "How we deal with this is how we deal with the future."7

Anthony Fauci, director of the National Institute of Allergy and Infectious Diseases, said it was important that the US has different vaccines and that testing increases. He said he favoured keeping schools open and said it could be done safely. He warned that a vaccine was not a substitute for public health measures, such as wearing a mask, physical distancing, avoiding crowds, and hand washing. Vaccine hesitancy made it difficult to reach herd immunity.

By the end of summer 2021, Fauci said, "we may have herd immunity" and life might be "close to normal by the end of 2021."

\section{Correction: On 14 December we changed the word "approve" in the title} to "authorise."

Mahase E. Covid-19: People with history of significant allergic reactions should not receive Pfizer vaccine, says regulator. $B M$ J 2020;371:m4780doi: 10.1136/bmj.m4780.

2 Pfizer. Our covid-19 vaccine study: what's next? 20 November 2020. www.pfizer.com/news/hot-topics/our_covid_19_vaccine_study_what_s_next.

3 Langreth R. Moderna offer US fail safe on vaccines if Pfizer falls short. Bloomberg.com. 10 December 2020. www.bloomberg.com/news/articles/2020-12-10/moderna-offers-u-s-fail-safe-on-vaccines-if-pfizer-fallsshort.

4 LaFraniere S, Thomas K, Weiland N. Trump administration officials passed when Pfizer offered months ago to sell the US more vaccine doses. New York Times. 7 December 2020. www.nytimes.com/2020/12/07/us/trumpcovid-vaccine-pfizer.html.

5 Covid-19 dashboard by the Center for Systems Science and Engineering at Johns Hopkins University. https://gisanddata.maps.arcgis.com/apps/opsdashboard/index.html\#/bda7594740fd40299423467b48e9ecf6.

$6 \quad$ New York Times. Coronavirus in the US: latest map and case count. 10 December 2020. www.nytimes.com/interactive/2020/us/coronavirus-us cases.html.

7 Harvard TH Chan School of Public Health. Covid-19: Chasing science to save lives. When public health means business. Part 6. 9 December 2020 https://harvard.az1.qualtrics.com/jfe/form/SV_esXw5M07mh5XB4h.

This article is made freely available for use in accordance with BMJ's website terms and conditions for the duration of the covid-19 pandemic or until otherwise determined by BMJ. You may use, download and print the article for any lawful, non-commercial purpose (including text and data mining) provided that all copyright notices and trade marks are retained. 